Check for updates

Cite this: Chem. Sci., 2019, 10, 4169

๑ All publication charges for this article have been paid for by the Royal Society of Chemistry

Received 17th January 2019

Accepted 27th February 2019

DOI: $10.1039 / c 9 s c 00278 b$

rsc.li/chemical-science

\section{Carbon monoxide insertion at a heavy p-block element: unprecedented formation of a cationic bismuth carbamoyl $\uparrow$}

\author{
Jacqueline Ramler, ${ }^{\mathrm{a}}$ Jordi Poater, (D) bc Florian Hirsch, ${ }^{\mathrm{d}}$ Benedikt Ritschel, ${ }^{\mathrm{a}}$ \\ Ingo Fischer, (D) ${ }^{d}$ F. Matthias Bickelhaupt (D) *ef and Crispin Lichtenberg (D) *a
}

\begin{abstract}
Major advances in the chemistry of 5th and 6th row heavy p-block element compounds have recently uncovered intriguing reactivity patterns towards small molecules such as $\mathrm{H}_{2}, \mathrm{CO}_{2}$, and ethylene. However, well-defined, homogeneous insertion reactions with carbon monoxide, one of the benchmark substrates in this field, have not been reported to date. We demonstrate here, that a cationic bismuth amide undergoes facile insertion of $\mathrm{CO}$ into the $\mathrm{Bi}-\mathrm{N}$ bond under mild conditions. This approach grants direct access to the first cationic bismuth carbamoyl species. Its characterization by NMR, IR, and UV/vis spectroscopy, elemental analysis, single-crystal X-ray analysis, cyclic voltammetry, and DFT calculations revealed intriguing properties, such as a reversible electron transfer at the bismuth center and an absorption feature at $353 \mathrm{~nm}$ ascribed to a transition involving $\sigma$ - and $\pi$-type orbitals of the bismuthcarbamoyl functionality. A combined experimental and theoretical approach provided insight into the mechanism of $\mathrm{CO}$ insertion. The substrate scope could be extended to isonitriles.
\end{abstract}

\section{Introduction}

The traditional distinction between transition metal and maingroup compounds according to their physical and chemical properties has recently been challenged. ${ }^{1}$ This is due to the fact that researchers are currently in the process of understanding how to design main group compounds with properties including a well-defined one-electron-redox chemistry, small HOMO-LUMO gaps of $<4 \mathrm{eV}$, and remarkable reactivities in the activation of small molecules such as $\mathrm{H}_{2}, \mathrm{CO}, \mathrm{CO}_{2}$, and ethylene.

Among the main group compounds, complexes of the heavy p-block elements with a principal quantum number of $n>4$

${ }^{a}$ Institute of Inorganic Chemistry, Julius-Maximilians Universität Würzburg, Am Hubland, 97074 Würzburg, Germany.E-mail: crispin.lichtenberg@uni-wuerzburg.de ${ }^{b}$ ICREA, Pg. Lluis Companys 23, 08010 Barcelona, Spain

'Universitat de Barcelona, Departament de Química Inorgànica i Orgànica \& IQTCUB, Martí i Franquès 1-11, 08028 Barcelona, Spain

${ }^{d}$ Institute of Physical Chemistry, Julius-Maximilians Universität Würzburg, Am Hubland, 97074 Würzburg, Germany

${ }^{e}$ Vrije Universiteit Amsterdam, Department of Theoretical Chemistry, Amsterdam Center for Multiscale Modeling (ACMM), The Netherlands. E-mail: f.m. bickelhaupt@vu.nl

${ }^{f}$ Radboud University, Institute for Molecules and Materials, Heyendaalseweg 135, 6525 AJ Nijmegen, The Netherlands

$\dagger$ Electronic supplementary information (ESI) available: Experimental procedures, details of DFT calculations, NMR, IR and UV/vis spectra, cyclic voltammograms, single crystal X-ray analysis data, coordinates of calculated structures. CCDC 1875340-1875343. For ESI and crystallographic data in CIF or other electronic format see DOI: $10.1039 / \mathrm{c} 9 \mathrm{sc} 00278 \mathrm{~b}$ show some inherent characteristics with high potential for applications in synthesis and catalysis. These include low homolytic bond dissociation energies, ${ }^{2}$ reversible homolytic bond cleavage/bond forming reactions, ${ }^{3}$ and large ionic radii, which allow for the design of cationic species with a considerable soft Lewis acidity. In the case of bismuth, a relatively low toxicity of the element and its complexes should also be noted. ${ }^{4}$ For compounds based on elements of the sixth row of the periodic table of the elements, relativistic effects come into play and may affect their physical and spectroscopic properties. ${ }^{5}$

When targeting highly reactive heavy main group species, low-valent compounds, complexes with element-element multiple bonds, and cationic species are promising candidates. However, the synthesis of such compounds may be extremely challenging. This is due to the inherent characteristics of heavy p-block elements, including (i) large ionic and covalent radii, which facilitate (unselective) oligomerization of low-valent species, (ii) relatively low redox potentials, which make overreduction a serious synthetic problem, (iii) disproportionation reactions of mono-cationic complexes, and (iv) difficulties in accessing extremely Lewis-acidic and Lewis-basic species.

Despite these challenges, considerable efforts in designing heavy main group species that undergo well-defined reactions with small molecules have been crowned with success. The distannyne $\mathrm{Sn}_{2} \mathrm{Aryl}_{2}$ has been shown to reversibly add two equivalents of ethylene across its $\mathrm{Sn} \equiv \mathrm{Sn}$ bond to give the corresponding distannane (Scheme 1a, Aryl $=\mathrm{C}_{6} \mathrm{H}_{3}-2,6\left(\mathrm{C}_{6} \mathrm{H}_{3}-2\right.$,6$\left.\left.\mathrm{iPr}_{2}\right)_{2}\right) .{ }^{6,7}$ This distannyne and closely related derivatives also react with dihydrogen to give a dinuclear tin species with two 
bridging hydride ligands, a reaction that has recently been shown to be reversible (Scheme $1 \mathrm{~b}$ ). ${ }^{8}$ In an alternative strategy without any E-E multiple bonding, the hypervalent bismuth compound $\mathrm{Bi}\left(\mathrm{C}_{6} \mathrm{H}_{4} \mathrm{CH}_{2}\right)_{2} \mathrm{~N} t \mathrm{Bu}(\mathrm{OMe})$ with one polar $\mathrm{Bi}-\mathrm{O}$ bond has been shown to undergo reversible $\mathrm{CO}_{2}$ fixation under mild reaction conditions (Scheme 1c). ${ }^{\mathbf{9}, \mathbf{1 0}}$

Apart from $\mathrm{H}_{2}, \mathrm{CO}_{2}$, and ethylene, carbon monoxide is an intriguing substrate for insertion chemistry, since it represents an attractive, versatile C1-building block in synthetic chemistry. Traditionally, its utilization for the synthesis of organic molecules such as alcohols, aldehydes, or carboxamides has been realized with transition metal carbonyl species acting as critical intermediates. ${ }^{\mathbf{1 1}}$ According to the Dewar-Chatt-Duncanson

\section{Heavy p-Block Elements}

\begin{tabular}{|c|c|c|c|c|}
\hline 49 & 50 & 51 & 52 & 53 \\
In & Sn & Sb & Te & I \\
\hline 81 & 82 & 83 & 84 & 85 \\
TI & Pb & Bi & Po & At \\
\hline
\end{tabular}

Previous Work:

a) Reversible Addition of Ethylene

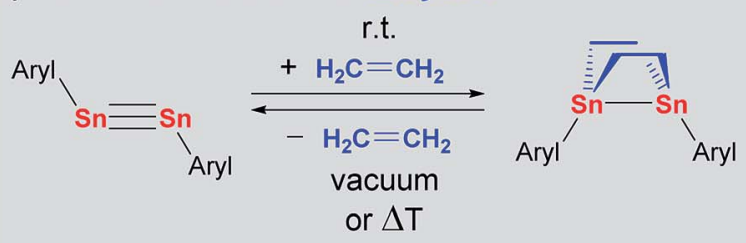

b) Addition of $\mathrm{H}_{2}$ (equilibrium at elevated temperatures)

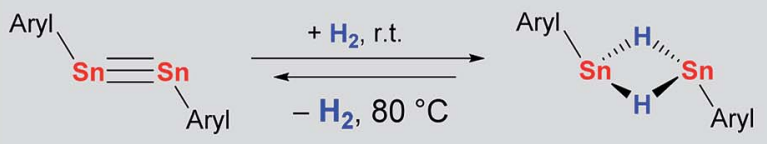

c) Reversible Fixation of $\mathrm{CO}_{2}$

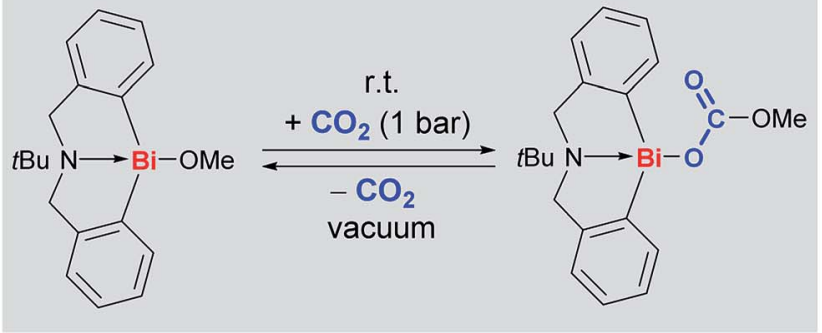

This Work:
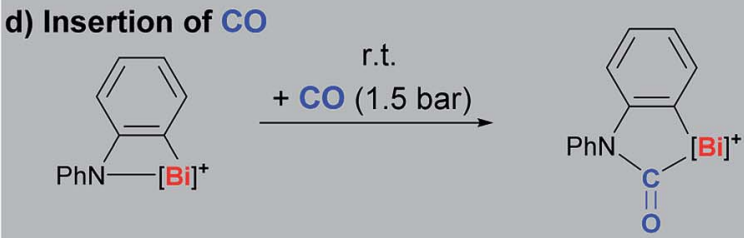

Scheme 1 Examples of well-defined compounds of heavy p-block elements that show unusual reactivity patterns towards small molecules. Aryl $=\mathrm{C}_{6} \mathrm{H}_{3}-2,6\left(\mathrm{C}_{6} \mathrm{H}_{3}-2,6-\mathrm{iPr}_{2}\right)_{2}$. model, the bond between $\mathrm{CO}$ and a transition metal constitutes of ligand-to-metal $\sigma$-donation and metal-to-ligand $\pi$-backdonation. It has been demonstrated that $\pi$-back-donation makes an important or even crucial contribution to the overall bonding energy of most synthetically relevant carbonyl compounds. ${ }^{12}$ This renders carbon monoxide an extremely challenging substrate for compounds based on heavy p-block elements, because synthetically accessible species of this kind usually lack occupied orbitals of sufficient symmetry and energy for $\pi$-back-donation. As a result, insights in this field of research are very limited. ${ }^{\mathbf{1 3 , 1 4}}$ Electrochemical sensing of CO at $\mathrm{SnO}_{2}$ or $\mathrm{In}_{2} \mathrm{O}_{3}$ surfaces at elevated temperatures has been related to the formation of carbonate and carboxylate species by IR spectroscopy. ${ }^{15}$ Matrix isolation techniques allowed for the IR spectroscopic characterization of tin and lead carbonyl species such as $\mathrm{SnCO}, \mathrm{Sn}(\mathrm{CO})_{2}, \mathrm{Sn}_{n} \mathrm{CO}, \mathrm{Pb}_{n} \mathrm{CO}$, and $\mathrm{SnCO}^{-}$at 7-20 K ( $n$ $=1-4) .{ }^{16}$ These reports have been complemented by additional purely theoretical studies on these and related compounds. ${ }^{17}$ To the best of our knowledge, however, well-defined insertion reactions of carbon monoxide with compounds based on heavy p-block elements showing a principal quantum number of $n>4$ have not been reported to date.

Cationic bismuth amides combine a considerable Lewis acidity with a good accessibility and a high reactivity, making them promising candidates for small molecule activation. ${ }^{\mathbf{1 8 - 2 0}}$ Insertion reactions with carbon monoxide in specific would grant direct access to cationic bismuth carbamoyls, an unprecedented structural motif with high potential for the stabilization of (intermediate) radical species (Scheme 1d). ${ }^{21}$

Here we demonstrate that a well-defined cationic bismuth amide undergoes highly selective and facile insertion reactions with carbon monoxide and isonitriles under mild conditions, yielding the first examples of cationic bismuth carbamoyls and amidinoyls, which were isolated and fully characterized.

\section{Results and discussion}

The dinuclear cationic bismuth compound $\left[\mathrm{Bi}_{2}\left(\mathrm{~N}\left(\mathrm{C}_{6} \mathrm{H}_{4}\right) \mathrm{Ph}\right)_{2}\right.$ $\left.(\mathrm{OTf})_{2}(\text { thf })_{3}\right]$ (1) has recently been reported and was synthesized according to the literature (Scheme 2; $\left.\mathrm{Tf}=\mathrm{SO}_{2} \mathrm{CF}_{3}\right){ }^{19 a, 22}$ The prominent structural feature of compound $\mathbf{1}$ is a fourmembered $\mathrm{C}_{2} \mathrm{NBi}$ ring. The geometric parameters dictated by

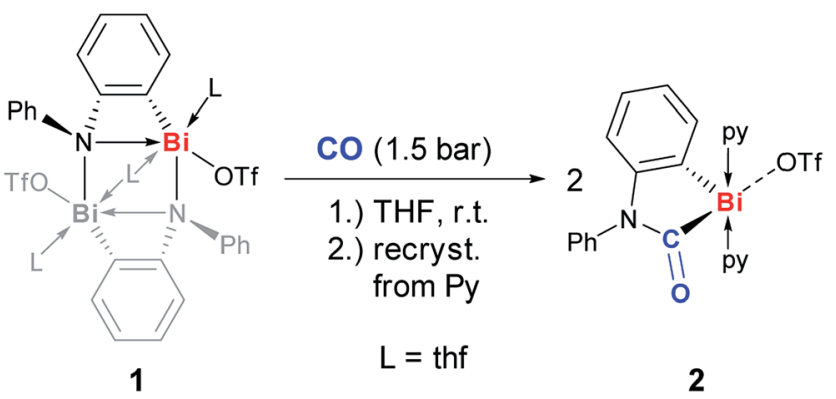

Scheme 2 Insertion of $\mathrm{CO}$ into $\mathrm{Bi}-\mathrm{N}$ bond of (masked) cationic bismuth amide 1 to give cationic bismuth carbamoyl compound 2; py $=$ pyridine, $\mathrm{Tf}=\mathrm{SO}_{2} \mathrm{CF}_{3}$. 
the phenylene unit suggest a considerable ring strain and lead to a significantly elongated $\mathrm{Bi}-\mathrm{N}$ bond as part of the fourmembered ring. ${ }^{19}$ These characteristics seem predetermined for compound $\mathbf{1}$ to be highly active in small molecule activation reactions. Thus, compound $\mathbf{1}$ was reacted with carbon monoxide, which represents an extraordinarily challenging substrate in the chemistry of heavier group 15 compounds. When a suspension of yellow 1 in THF was exposed to an atmosphere of 1.5 bar $\mathrm{CO}$ the precipitation of a pale yellow solid indicated the consumption of the starting materials. Whereas a quantitative reaction monitoring by IR and NMR spectroscopy was hampered by the moderate to poor solubility of the starting material and the product in THF, these methods still indicated significant conversion of 1 after $1 \mathrm{~h}$. However, extended reaction times of $2 \mathrm{~d}$ were necessary to reach full conversion of 1 , which was otherwise difficult to separate from the product. Recrystallization of the crude precipitate from pyridine/ $/ \mathrm{Et}_{2} \mathrm{O} /$ pentane gave the insertion product 2 in $61 \%$ yield (Scheme 2). ${ }^{23}$ Compound 2 is moderately soluble in THF, but adequately soluble in pyridine. In pyridine solution, it is stable at ambient temperature and under ambient lighting for at least five weeks and at $80{ }^{\circ} \mathrm{C}$ for at least $2 \mathrm{~h}$. NMR spectroscopy indicated the substitutional lability of the pyridine ligands, which can be removed in vacuo at $80{ }^{\circ} \mathrm{C}$. ${ }^{1} \mathrm{H}$ and ${ }^{13} \mathrm{C}$ and ${ }^{19} \mathrm{~F}$ NMR spectroscopic analyses revealed the expected signal patterns for the functional groups present in $\mathbf{2}$ (a phenylene and a phenyl group, two pyridine ligands, and a triflate). An unusually large ${ }^{13} \mathrm{C}$ NMR chemical shift of 251 ppm was recorded for the $C \mathrm{ONR}_{2}$ group, which was ascribed to its interaction with the Lewis acidic cationic bismuth center. ${ }^{24}$ IR spectroscopic analyses revealed a CO stretching frequency of $1637 \mathrm{~cm}^{-1}$ for the carbamoyl functional group. This is close to those reported for carbamoyl compounds of $\mathrm{Sn}$ and $\mathrm{Pb}$, which were prepared by classical salt elimination protocols. ${ }^{25}$

The molecular structure of $\mathbf{2}$ was unambiguously identified by single-crystal X-ray diffraction (monoclinic space group $P 2_{1} / n$ with $Z=4$; Fig. 1). This confirmed the insertion of CO into the former $\mathrm{Bi}-\mathrm{N}$ bond, resulting in formation of a bismuth carbamoyl moiety, an unprecedented structural motif. ${ }^{26}$ The Bi1-C13 bond is considerably longer than the Bi1-C2 bond $(\Delta=+0.11$ $\AA)$. Despite the cationic nature of $2,{ }^{22}$ the $\mathrm{Bi}-\left(\mathrm{CONR}_{2}\right)$ bond length is in the same range as that of electronically stabilized $\mathrm{Bi}-\mathrm{C}$ bonds in neutral compounds such as $\mathrm{Bi}\left(\mathrm{CH}\left(\mathrm{SiMe}_{3}\right)_{2}\right)_{3}$, $\mathrm{Bi}\left(\eta^{1}-2-\mathrm{Me}-\text { allyl }\right)_{3}$, or $\mathrm{Bi}\left(\mathrm{CF}_{2} \mathrm{CF}_{3}\right)_{3} \cdot{ }^{27}$ Accordingly, the C13-N1 distance of $1.38 \AA$ is in agreement with a partial $\mathrm{C}=\mathrm{N}$ double bond character. According to an energy decomposition analysis (EDA) of 2 and related species, these differences in $\mathrm{Bi}-\mathrm{C}$ bond lengths are also reflected by the corresponding interaction energies: in homolytic bond dissociations, the interaction energy of the Bi-Aryl bond is $17.9 \mathrm{kcal} \mathrm{mol}^{-1}$ larger than that of the $\mathrm{Bi}-\mathrm{CONR}_{2}$ bond (ESI $\dagger$ ). The covalent character of both types of bonds amounts to $44-49 \%$ according to EDA. In the solid state, 2 forms a loosely associated contact ion pair. The Bi1 $\cdots \mathrm{O} 2$ distance of $3.16 \AA$ is $12 \%$ below the sum of the van-der-Waals radii, but significantly elongated compared to the $\mathrm{Bi}-\mathrm{OTf}$ bond of $2.37 \AA$ in starting material $1 .^{19 a}$ The coordination geometry around the bismuth center in 2 is saturated by two

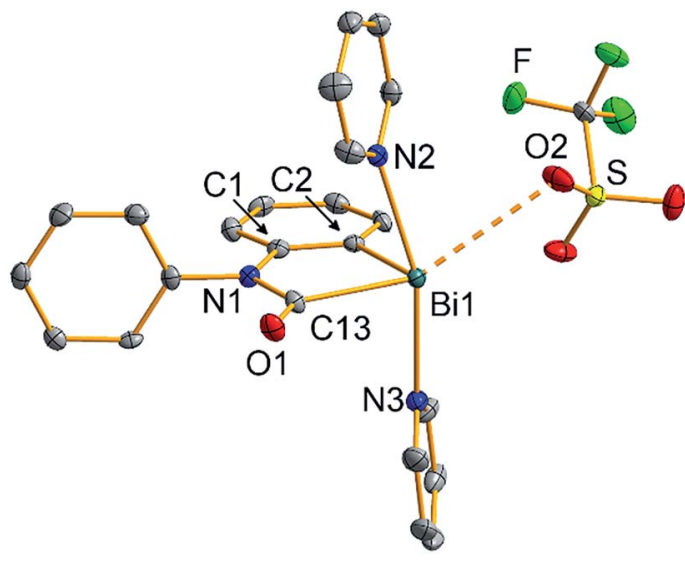

Fig. 1 Molecular structure of $\left[\mathrm{Bi}\left(\mathrm{CONPh}\left(\mathrm{C}_{6} \mathrm{H}_{4}\right)\right)\left(\mathrm{NC}_{5} \mathrm{H}_{5}\right)_{2}\right][\mathrm{OTf}]$ (2) in the solid state. Displacement ellipsoids are shown at the $50 \%$ probability level. Hydrogen atoms are omitted for clarity. Selected bond lengths $(\AA)$ and angles $\left({ }^{\circ}\right)$ : Bi1-C2, 2.227(5); Bi1-C13, 2.335(5); Bi1-N2,

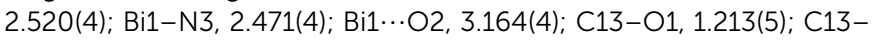
$\mathrm{N} 1,1.382(6) ; \mathrm{C} 2-\mathrm{Bi} 1-\mathrm{C} 13,76.60(16) ; \mathrm{C} 2-\mathrm{Bi1}-\mathrm{N} 2,84.21(15) ; \mathrm{C} 2-\mathrm{Bi} 1 \ldots$ $\mathrm{O} 2,103.25(14) ; \mathrm{N} 2-\mathrm{Bi} 1-\mathrm{N} 3,163.56(13) ; \mathrm{C} 13-\mathrm{Bi} 1 \cdots \mathrm{O} 2,153.50(14) ; \tau_{5}=$ 0.17 .

pyridine ligands in trans-position to each other. Overall, this results in a distorted square pyramidal coordination geometry around bismuth with $\mathrm{C} 2$ in the apical position $\left(\tau_{5}=0.17\right){ }^{28}$

The electrochemical behavior of 2 was investigated by cyclic voltammetry in THF/0.1 M $\left[\mathrm{N}(n \mathrm{Bu})_{4}\right]\left[\mathrm{PF}_{6}\right]$ at $23{ }^{\circ} \mathrm{C}$, which revealed a chemically reversible redox event at an only moderately negative potential of $-1.66 \mathrm{~V} v s$. Fc/Fc ${ }^{+}$(Fig. 2a and ESI; $\dagger$ $\left.\mathrm{Fc}=\mathrm{Fe}\left(\mathrm{C}_{5} \mathrm{H}_{5}\right)_{2}\right)$. According to DFT calculations, the radical generated upon reduction is free of neutral donor ligands, $\left[\mathrm{Bi}\left(\mathrm{CONPh}\left(\mathrm{C}_{6} \mathrm{H}_{4}\right)\right)\right]^{\bullet}$ (2red). $74 \%$ of the spin density are located at the bismuth center, occupying a molecular orbital with dominating contributions from a Bi-6p-type atomic orbital (Fig. $2 \mathrm{~b}$ and ESI $\dagger$ ). The remaining spin density is delocalized over the phenylene and the carbamoyl unit of 2red, with spin densities of up to $5 \%$ at single $\mathrm{C}, \mathrm{N}$, and $\mathrm{O}$ atoms. This delocalization of spin density is believed to contribute to the stability of this species under the conditions of the

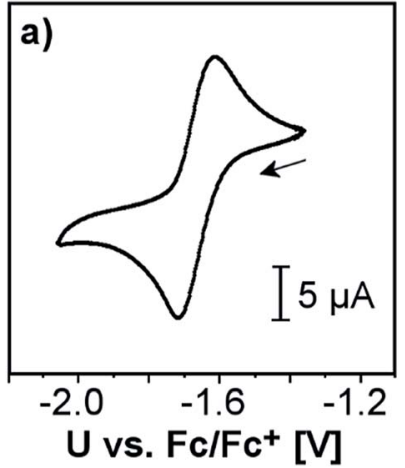

b)

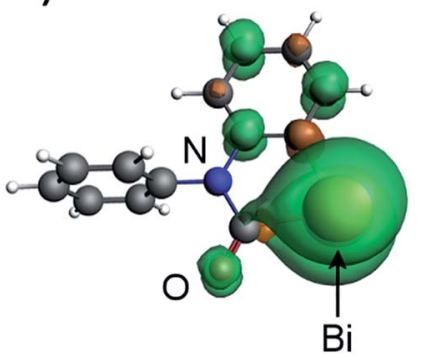

Fig. 2 (a) Cyclic voltammogram of 2 in THF/0.1 $\mathrm{M}\left[\mathrm{N}(n \mathrm{Bu})_{4}\right]\left[\mathrm{PF}_{6}\right]$ at $23{ }^{\circ} \mathrm{C}$ with a scan rate of $500 \mathrm{mV} \mathrm{s}^{-1} ; \mathrm{FC}=\mathrm{Fe}\left(\mathrm{C}_{5} \mathrm{H}_{5}\right)_{2}$. (b) Optimized geometry and spin density distribution (iso value $=0.001$ ) of reduced species $\left[\mathrm{Bi}\left(\mathrm{CONPh}\left(\mathrm{C}_{6} \mathrm{H}_{4}\right)\right)\right]^{\bullet}(2 \mathrm{red})$. 
electrochemical experiment. While two examples of isolable $\mathrm{Bi}^{\mathrm{II}}$ radical species and one example of a persistent $\mathrm{Bi}^{\mathrm{II}}$ radical species have recently been reported, ${ }^{3 a, 29}$ this is the first example of a quasi-reversible electron transfer at a mononuclear bismuth compound with the bismuth atom being the major spin carrier, demonstrating the potential of the bismuth carbamoyl functional group for the stabilization of (intermediate) radical species. ${ }^{30}$ The pale yellow compound 2 was further investigated by UV/vis spectroscopy in THF solution, which revealed a broad absorption band at $\lambda_{\max }=353 \mathrm{~nm}(\mathrm{FWHM}=$ $96 \mathrm{~nm}$; Fig. 3). In dilute solutions, the substitutionally labile

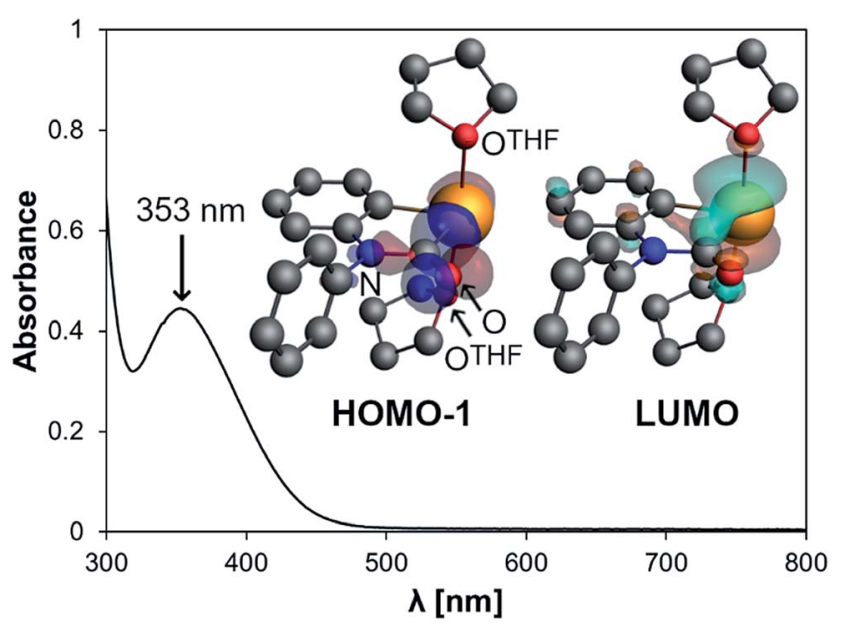

Fig. $3 \mathrm{UV} /$ vis spectrum of $2(0.4 \mathrm{mM}$ solution in THF) and orbitals involved in the transition at $353 \mathrm{~nm}$ according to TD-DFT calculations on $\left[\mathrm{Bi}\left(\mathrm{CONPh}\left(\mathrm{C}_{6} \mathrm{H}_{4}\right)\right)(\text { thf })_{2}\right]^{+}$. pyridine ligands of 2 can presumably be exchanged for thf ligands (ESI $\dagger$ ). TD-DFT calculations at the CAMY-B3LYP/TZ2P level of theory on $\left[\mathrm{Bi}\left(\mathrm{CONPh}\left(\mathrm{C}_{6} \mathrm{H}_{4}\right)\right)(\text { thf })_{2}\right]^{+}$indicated a HOMO-1/LUMO singlet-singlet transition at $\lambda=354 \mathrm{~nm}$, when spin-orbit-coupling was taken into account using perturbation theory (for details see ESI $\dagger$ ). This transition is suggested to correspond to the experimentally observed band at $\lambda_{\max }=353 \mathrm{~nm}$. The HOMO-1 shows major contributions by orbitals forming the $\mathrm{Bi}-\mathrm{C}$ and $\mathrm{C}-\mathrm{N} \sigma$-bonds in the carbamoyl group and by an oxygen-centered p-type orbital. The LUMO consists of a bismuth-centered p-orbital and the $\tau^{*}$-orbital of the CO group, both of which are orthogonal to the plane defined by the carbamoyl functionality. Thus, the bismuth carbamoyl functional group is directly involved in the electronic transition that is triggered by light in the UV/vis region $(\lambda \approx 310-400 \mathrm{~nm})$.

The mechanism of CO insertion was investigated by DFT calculations (Scheme 3, for details see ESI $\dagger$ ). ${ }^{31}$ All values are given in $\mathrm{kcal} \mathrm{mol}^{-1}$. We suggest coordination of CO to a Lewisacidic bismuth center to be the initiating reaction step leading to intermediate $\mathbf{I}-\mathbf{1}(\Delta H:+9.7 ; \Delta G:+5.9) .{ }^{32}$ Insertion of the CO molecule proceeds via transition state TS-1, in which the CO unit bridges a $\mathrm{Bi}$ and an $\mathrm{N}$ atom (barrier: $\Delta H^{\neq}:+8.5 ; \Delta G^{\neq}$: +10.5 ), to give intermediate $\mathbf{I}-2$ in an almost thermoneutral reaction $(\Delta H:+0.2 ; \Delta G:+3.0)$. A similar sequence of COcoordination (to give $\mathbf{I}-\mathbf{3}$ ) and formation of a transition state with a $\mathrm{Bi} \cdots(\mathrm{CO}) \cdots \mathrm{N}$ unit (TS-2, barrier: $\left.\Delta H^{\neq}:+9.3 ; \Delta G^{\neq}:+11.6\right)$ and insertion leads to dinuclear intermediate $\mathbf{I}-\mathbf{4}$. Coordination of THF gives the monomeric compound $\mathbf{I - 5}$, which is suggested to be the species that precipitates from the reaction mixture, when 1 is reacted with CO in THF (vide supra). ${ }^{23}$ Up to this point the overall reaction is exothermic and endergonic according to

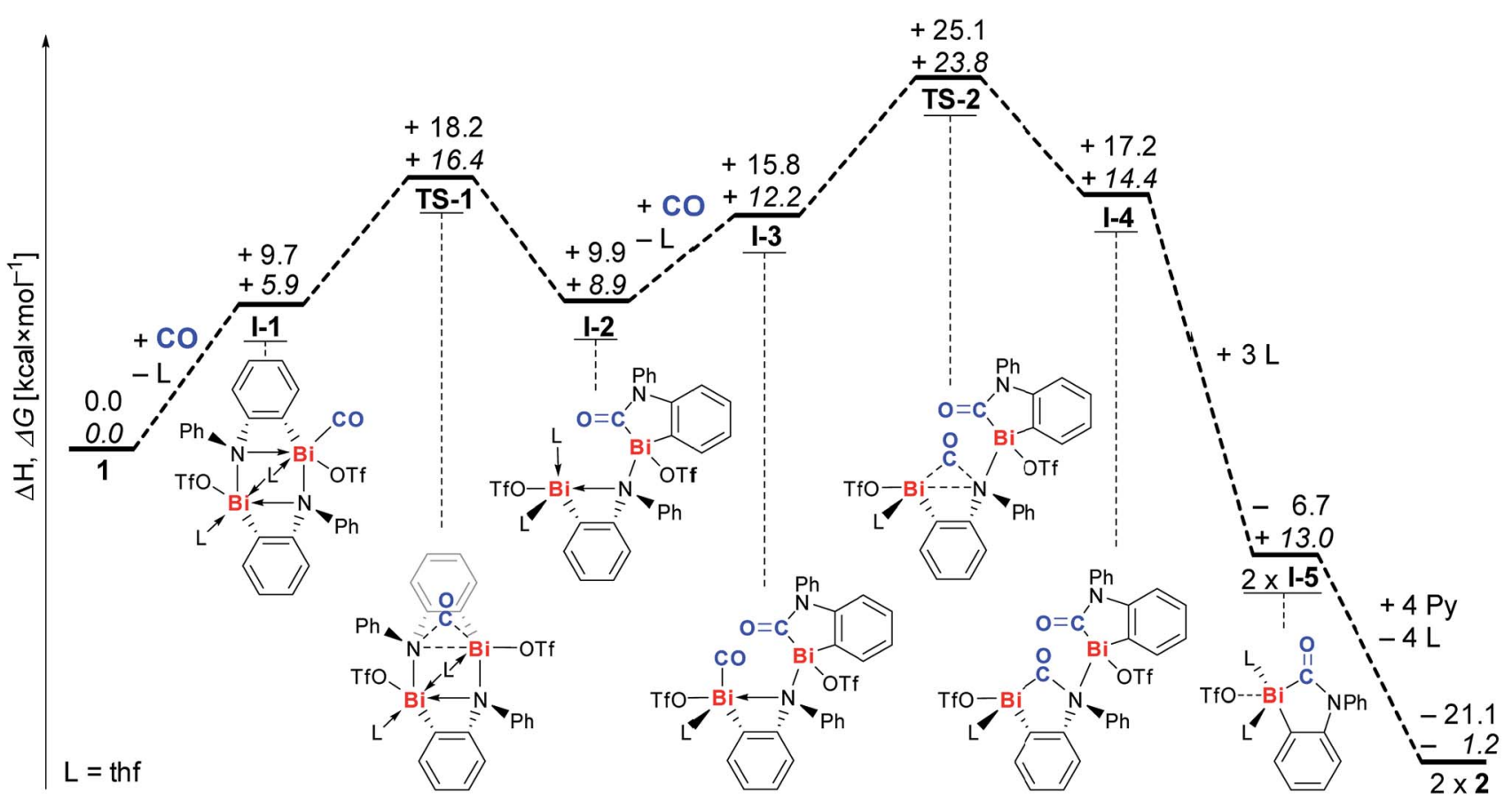

Scheme 3 Proposed mechanism for reaction of 1 with $C O$ to give insertion product 2; $\Delta H$ values (regular font) and $\Delta G$ values (italic) are given in $\mathrm{kcal} \mathrm{mol}^{-1}$. $\mathrm{L}=$ thf. 
DFT calculations ( $\Delta H:-6.7 ; \Delta G:+13.0)$, and the formation of I-5 is presumably aided by its poor solubility in THF. The exchange of THF for pyridine ligands to give isolated product 2 is exothermal and exergonic, reflecting the Lewis acidity of the bismuth atom $(\Delta H:-14.4 ; \Delta G:-14.2)$. Monitoring the reaction by IR spectroscopy indicated the accumulation of I-5 in solution until its saturation concentration was reached (characteristic band at $\left.1592 \mathrm{~cm}^{-1}\right) .{ }^{23}$ Whereas intermediates $\mathbf{I}-\mathbf{1}, \mathbf{I}-\mathbf{2}$, and $\mathbf{I}-\mathbf{3}$ could not unambiguously be identified due to their low concentrations, signal overlapping, or their short-lived character, bands at 1655 and $1669 \mathrm{~cm}^{-1}$ were tentatively assigned to intermediate I-4 (ESI $\left.{ }^{\dagger}\right)$.

Putting the unusual reactivity of $\mathbf{1}$ towards carbon monoxide into the broader context of main group chemistry reveals some remarkable points. Compounds of strongly electropositive elements of Groups 1 and 2, as well as light(er) elements of Group 13 (B-Ga) undergo insertion with CO; examples include species such as $n \mathrm{BuLi}, \mathrm{LiN}(\mathrm{iPr})_{2}, \mathrm{MgEtBr}$, or $\mathrm{Al}(t \mathrm{Bu})_{3} .^{33,34}$ These reactivity patterns may be interpreted as a result of the strong polarization of the $\mathrm{M}-\mathrm{X}$ bond $(\mathrm{X}=\mathrm{C}, \mathrm{N})$ and the high Lewis acidity of the main-group compound. In addition, compounds of Group 13 and 14 elements with low-valent character or with $\mathrm{E}-\mathrm{E}$ (single or multiple) bonds have been reported to undergo intriguing insertion reactions with carbon monoxide $(\mathrm{E}=$ Group 13/14 element). Examples include diborynes, diboracumulenes, carbenes, germylenes and a disila-Dewarbenzene. ${ }^{35-37}$ When it comes to well-defined compounds of the pnictogens $\mathrm{P}-\mathrm{Bi}$, selective insertion reactions with $\mathrm{CO}$ under mild conditions have only been reported for phosphorous species. Two different strategies have been reported in this context. Frustrated Lewis pairs (FLPs) with a phosphane moiety as the Lewis basic component react with $\mathrm{CO}$ under mild conditions to form heterocyclic compounds. ${ }^{38-43}$ The second strategy exploits the reactivity of a phosphorus biradicaloid, which inserts $\mathrm{CO}$ under harsher conditions to give a $\mathrm{P}_{2} \mathrm{~N}_{2} \mathrm{C}$ ring motif that maintains the biradicaloid character. ${ }^{44}$ Overall, compound 1 represents the first molecular heavy p-block compound $(n>4)$ to undergo a direct and well-defined insertion reaction with carbon monoxide under mild conditions. The Lewis acidity and geometric constraints of $\mathbf{1}$ play key roles in determining its remarkable reactivity. It may be considered to interpret these driving forces in terms of FLP chemistry with a Lewis basic $\mathrm{N}$ and a Lewis acidic Bi site. ${ }^{45 c, d}$ To the best of our knowledge, this would be the first example of FLP chemistry of molecular compounds being extended to the heavy main group element bismuth. ${ }^{45-47}$

In order to extend the scope of the unusual insertion reactions of 1 with unsaturated small molecules, isonitriles were targeted due to their isoelectronic and isolobal relationship with carbon monoxide. Well-defined insertion reactions of pnictogen compounds with isonitriles are rare. Transition metal-stabilized phosphinidenes and arsinidenes $\left[\mathrm{E}\left(\mathrm{C}_{5} \mathrm{Me}_{5}\right)\right.$ $\left.\left(\mathrm{W}(\mathrm{CO})_{5}\right)_{2}\right](\mathrm{E}=\mathrm{P}$, As) have been reported to coordinate sterically demanding $\mathrm{C} \equiv \mathrm{N} t \mathrm{Bu}$ and to undergo insertion reactions with less bulky isonitriles $\mathrm{C} \equiv \mathrm{NR}(\mathrm{R}=$ cyclo-hexyl, $n \mathrm{Bu}) \cdot{ }^{48}$ Only recently, the first example of an insertion reaction between a bismuth compound and an isonitrile has been documented:

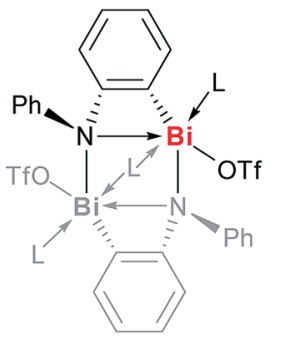

1

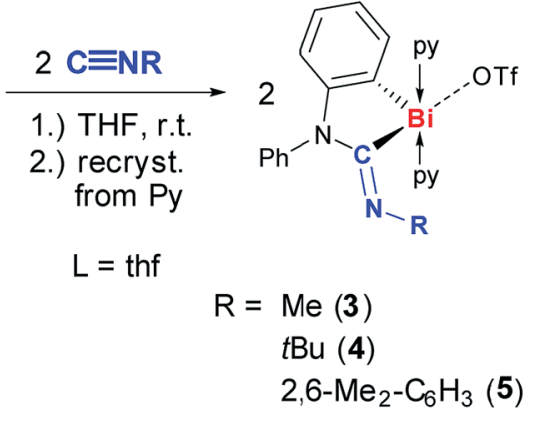

Scheme 4 Insertion of $\mathrm{C} \equiv \mathrm{NR}$ into $\mathrm{Bi}-\mathrm{N}$ bond of (masked) cationic bismuth amide 1 to give cationic bismuth amidinoyl compounds 3, 4, and 5; py = pyridine, $\mathrm{Tf}=\mathrm{SO}_{2} \mathrm{CF}_{3}$.

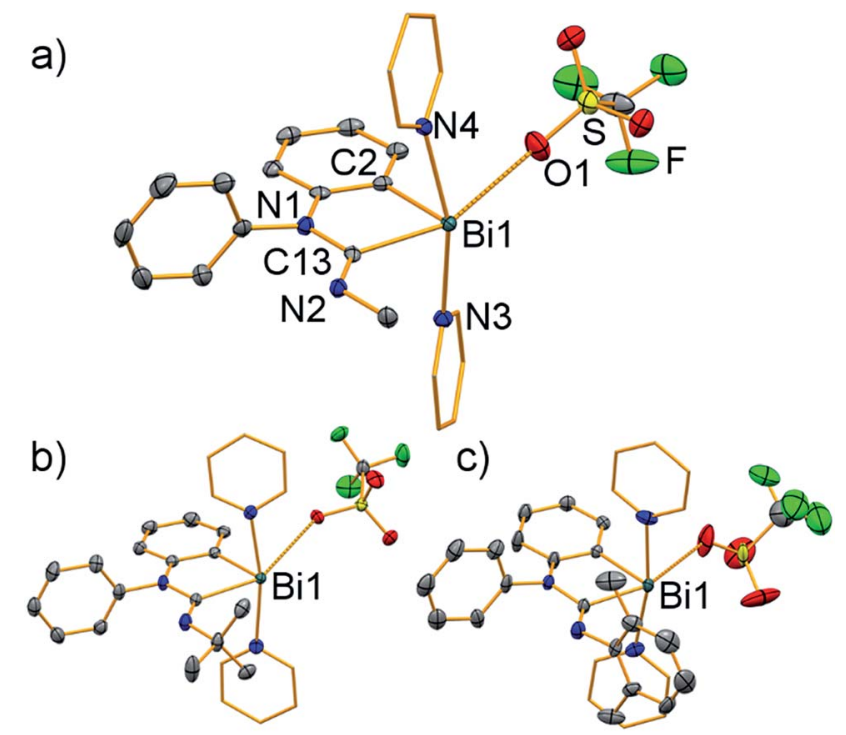

Fig. 4 Molecular structures of $\left[\mathrm{Bi}\left(\mathrm{CNRNPh}\left(\mathrm{C}_{6} \mathrm{H}_{4}\right)\right)\left(\mathrm{NC}_{5} \mathrm{H}_{5}\right)_{2}\right][\mathrm{OTf}]$ in the solid state ((a) $3(\mathrm{R}=\mathrm{Me})$; (b) $4(\mathrm{R}=t \mathrm{Bu})$; (c) $5\left(\mathrm{R}=2,6-\mathrm{Me}_{2}-\mathrm{C}_{6} \mathrm{H}_{3}\right)$ ). Displacement ellipsoids are shown at the $50 \%$ probability level; carbon atoms of pyridine ligands are shown as wireframe for clarity. Hydrogen atoms, lattice-bound solvent molecules, and split positions of disordered groups in (c) are omitted for clarity. Atom labelling in (b) and (c) is in analogy with that in (a). Selected bond lengths $(\AA)$ and angles $\left(^{\circ}\right)$ : (a) Bi1-C2, 2.222(3); Bi1-C13, 2.305(3); Bi1-N3, 2.499(2); Bi1-N4,

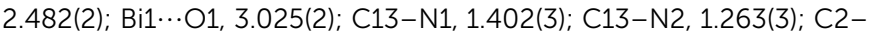
$\mathrm{Bi1}-\mathrm{C} 13,76.84(10) ; \mathrm{C} 2-\mathrm{Bi1}-\mathrm{N} 3,84.48(8) ; \mathrm{C} 2-\mathrm{Bi1} \cdots \mathrm{O} 1,79.86(9) ; \mathrm{N3}-$

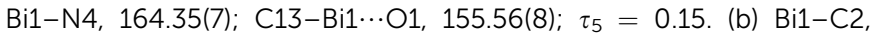
2.225(3); Bi1-C13, 2.331(3); Bi1-N3, 2.485(3); Bi1-N4, 2.525(3); Bi1 $\cdots$ O1, 2.997(2); C13-N1, 1.415(4); C13-N2, 1.261(4); C2-Bi1-C13, 77.35(12); C2-Bi1-N3, 87.63(11); C2-Bi1 ․o 1, 80.94(10); N3-Bi1-N4, 169.39(9); $\mathrm{C} 13-\mathrm{Bi1} \cdots \mathrm{O} 1,153.18(9) ; \tau_{5}=0.27$. (c) Bi1-C2, 2.202(4); Bi1C13, 2.299(4); Bi1-N3, 2.510(4); Bi1-N4, 2.488(4); Bi1...O1, 2.907(15); C13-N1, 1.43(2); C13-N2, 1.269(6); C2-Bi1-C13, 76.89(15); C2-Bi1-

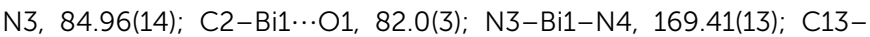
$\mathrm{Bi1} \cdots \mathrm{O} 1,158.8(3) ; \tau_{5}=0.18$.

the strongly nucleophilic nature of the boryl group in $\left[\mathrm{Ph}_{2}-\right.$ $\left.\mathrm{Bi}\left(\mathrm{BR}_{2}\right)\right]$ allowed for isolation of the insertion product $\left[\mathrm{Ph}_{2}-\right.$ $\left.\mathrm{Bi}\left(\mathrm{C}(\mathrm{NPh}) \mathrm{BR}_{2}\right)\right]$ in $22 \%$ yield, when $\mathrm{C} \equiv \mathrm{NPh}$ was used as the substrate $\left(\mathrm{BR}_{2}=1,2,4,3\right.$-triazaborol-3-yl) ${ }^{49}$ Remarkably, the 
alkyl isonitrile $\mathrm{C} \equiv \mathrm{N}(n \mathrm{Bu})$ was found to undergo fragmentation with formation of $\left[\mathrm{BiPh}_{2}(n \mathrm{Bu})\right]$, implying that isonitrile insertion is not a general reaction pathway for this bismuth boryl compound.

At ambient temperature, compound 1 readily reacted with isonitriles, $\mathrm{C} \equiv \mathrm{NR}$, that bear alkyl or aryl substituents with a steric profile varying from extremely low $(\mathrm{R}=\mathrm{Me})$ to high $(\mathrm{R}=$ $t \mathrm{Bu}, 2,6-\mathrm{Me}_{2}-\mathrm{C}_{6} \mathrm{H}_{3}$ ) (Scheme 4). Monitoring the reaction by ${ }^{1} \mathrm{H}-$ NMR spectroscopy in the case of $\mathrm{R}=t \mathrm{Bu}$ revealed full conversion within $10 \mathrm{~min}$ and a high spectroscopic yield of $>95 \%$. The insertion products 3-5 were isolated in 60-79\% yield after recrystallization from pyridine and fully characterized (Scheme 4, Fig. 4). In all cases the bismuth amidinoyl moiety was exclusively formed in its $Z$-configuration according to NMR spectroscopy. Compounds 3-5 show ${ }^{13} \mathrm{C}$ NMR chemical shifts between 210 and $223 \mathrm{ppm}$ and IR bands at $1606-1637 \mathrm{~cm}^{-1}$ for the $C \mathrm{NRNR}_{2}$ functionality.

Single-crystal X-ray diffraction analyses revealed a very similar coordination behavior for compounds 3-5 (Fig. 4). In each case, the bismuth atom is found in distorted square pyramidal coordination geometry with $\mathrm{C} 2$ in the apical position $\left(\tau_{5}=0.15-0.27\right)$. The Bi-C distances of the amidinoyl unit (Bi1C13, 2.30-2.33 $\AA$ ) are significantly larger than those involving the aryl group (Bi1-C2, 2.20-2.23 $\mathrm{A}$ ). The N1-C13 bond lengths of 1.40-1.43 A suggest partial double bond character, albeit they are larger than those in carbamoyl compound 2 (1.38 $\AA$ ).

\section{Conclusions}

In summary, we have reported the facile insertion of carbon monoxide into a bismuth-nitrogen bond, exploiting the Lewis acidity of the cationic bismuth compound and the release of ring strain as driving forces of the reaction. To the best of our knowledge, this is the first example of a molecular compound based on a heavy p-block element with the principal quantum number $n>4$ to undergo a well-defined insertion reaction with carbon monoxide under mild conditions. This grants access to a novel cationic bismuth carbamoyl species, which allows for the first time to realize a chemically reversible redox process at the bismuth center of a mononuclear molecular compound. The pale yellow color of this compound was attributed to a singlet-singlettransition that involves the bismuth carbamoyl functionality and is facilitated by spin-orbit coupling. Isonitriles were shown to analogously undergo these unusual insertion reactions. These results reveal the potential of heavy main group compounds in small-molecule activation, reversible electron-transfer reactions at heavy main group elements, and photochemistry targeting the accessibility of excited states with visible light.

\section{Conflicts of interest}

There are no conflicts to declare.

\section{Acknowledgements}

C. L. thanks Dr R. D. Dewhurst for helpful discussions and Prof. H. Braunschweig for continuous support. Funding by the Fonds der Chemischen Industrie (Liebig fellowship to C. L.), the DFG (funding to C. L. and GRK 2112), the Netherlands Organization for Scientific Research (NWO), the Catalan Government (2017SGR348), and the Spanish MINECO (CTQ2016-77558-R and MDM-2017-0767) is acknowledged.

\section{Notes and references}

1 (a) P. P. Power, Nature, 2010, 463, 171-177; (b) P. P. Power, Chem. Rev., 2003, 103, 789-809; (c) D. Martin, M. Soleilhavoup and G. Bertrand, Chem. Sci., 2011, 2, 389399; (d) M.-A. Légaré, C. Pranckevicius, H. Braunschweig, Chem. Rev. DOI: 10.1021/acs.chemrev.8b00561; (e) C. Lichtenberg, Angew. Chem., Int. Ed., 2016, 55, 484-486; (f) C. Weetman, S. Inoue, ChemCatChem, 2019, 10, 42134228.

2 E.g.: (a) L. D. Freedman and G. O. Doak, Chem. Rev., 1982, 82, 15-57; (b) G. P. Smith and R. Patrick, Int. J. Chem. Kinet., 1983, 15, 167-185 and references therein.

3 E.g.: (a) S. Ishida, F. Hirakawa, K. Furukawa, K. Yoza and T. Iwamoto, Angew. Chem., Int. Ed., 2014, 53, 11172-11176; (b) D. Dakternieks, D. J. Henry and C. H. Schiesser, Organometallics, 1998, 17, 1079-1084; (c) M. Lehnig and K. Dören, J. Organomet. Chem., 1981, 210, 331-341.

4 E.g.: J. M. Bothwell, S. W. Krabbe and R. S. Mohan, Chem. Soc. Rev., 2011, 40, 4649-4707 and references therein.

5 (a) P. Pyykkö, Chem. Rev., 1988, 88, 563-594; (b) P. Pyykkö, Annu. Rev. Phys. Chem., 2012, 63, 45-64; (c) R. J. F. Berger, D. Rettenwander, S. Spirk, C. Wolf, M. Patzschke, M. Ertl, U. Monkowius and N. W. Mitzel, Phys. Chem. Chem. Phys., 2012, 14, 15520-15524; (d) A. Wodyński, O. L. Malkina and M. Pecul, J. Phys. Chem. A, 2016, 120, 5624-5634.

6 Y. Peng, B. D. Ellis, X. Wang, J. C. Fettinger and P. P. Power, Science, 2009, 325, 1668-1670.

7 For the insertion of ethylene into the $\mathrm{Sn}-\mathrm{C}$ bond of a diarylstannylen see: T. Y. Lai, J.-D. Guo, J. C. Fettinger, S. Nagase and P. P. Power, Chem. Commun., 2019, 55, 405407.

8 (a) Y. Peng, M. Brynda, B. D. Ellis, J. C. Fettinger, E. Rivard and P. P. Power, Chem. Commun., 2008, 6042-6044; (b) S. Wang, T. J. Sherbow, L. A. Berben and P. P. Power, J. Am. Chem. Soc., 2018, 140, 590-593.

9 S.-F. Yin, J. Maruyama, T. Yamashita and S. Shimada, Angew. Chem., Int. Ed., 2008, 47, 6590-6593.

10 For reactions of $\mathrm{CO}_{2}$ with bismuth compounds, also see: (a) H. J. Breunig, L. Königsmann, E. Lork, M. Nema, N. Philipp, C. Silvestru, A. Soran, R. A. Varga and R. Wagner, Dalton Trans., 2008, 1831-1842; (b) K. Wójcik, T. Rüffer, H. Lang, A. A. Auer and M. Mehring, J. Organomet. Chem., 2011, 696, 1647-1651; (c) D. R. Kindra, I. J. Casely, M. E. Fieser, J. W. Ziller, F. Furche and W. J. Evans, J. Am. Chem. Soc., 2013, 135, 7777-7787.

11 (a) H. T. Luk, C. Mondelli, D. C. Ferré, J. A. Stewart and J. Pérez-Ramírez, Chem. Soc. Rev., 2017, 46, 1358-1426; (b) N. Rajesh, N. Basu and B. Sundararaju, Tetrahedron Lett., 2018, 59, 862-868; (c) A. S. Veige, Polyhedron, 2008, 27, $3177-3189$. 
12 (a) K. Nakashima, X. Zhang, M. Xiang, Y. Lin, M. Lin and Y. Mo, J. Theor. Comput. Chem., 2008, 7, 639-654; (b) G. Bistoni, S. Rampino, N. Scafuri, G. Ciancaleoni, D. Zuccaccia, L. Belpassi and F. Tarantelli, Chem. Sci., 2016, 7, 1174-1184; (c) A. Diefenbach, F. M. Bickelhaupt and G. Frenking, J. Am. Chem. Soc., 2000, 122, 6449-6458.

13 Iodine reacts with carbon monoxide and water to give carbon dioxide and hydrogen iodide: W. M. MacNevin and W. N. Carson Jr, J. Am. Chem. Soc., 1950, 72, 42-44.

14 Laser photolysis of $\mathrm{HI}$ in a carbon monoxide matrix allows for the detection of the formyl radical: J. A. Brivati, N. Keen and M. C. R. Symons, J. Chem. Soc., 1962, 237-243.

15 (a) P. G. Harrison and M. J. Willet, Nature, 1988, 332, 337339; (b) M.-I. Baraton, L. Merhari, H. Ferkel and J.-F. Castagnet, Mater. Sci. Eng., C, 2002, 19, 315-321.

16 (a) A. Bos, J. Chem. Soc., Chem. Commun., 1972, 26-27; (b) L. N. Zhang, J. Dong and M. F. Zhou, J. Chem. Phys., 2000, 113, 8700-8705; (c) L. Jiang and X. Qiang, Bull. Chem. Soc. Jpn., 2006, 79, 857-863; (d) L. Jiang and Q. Xu, J. Chem. Phys., 2005, 122, 034506.

17 (a) Y. Lu, H. Wang, Y. Xie, H. Liu and H. F. Schaefer, Inorg. Chem., 2014, 53, 6252-6256; (b) C. Gourlaouen, O. Parisel and J.-P. Piquemal, J. Chem. Phys., 2010, 133, 124310; (c) A. J. Bridgeman, Inorg. Chim. Acta, 2001, 321, 27-41.

18 H. Dengel and C. Lichtenberg, Chem.-Eur. J., 2016, 22, 18465-18475.

19 (a) B. Ritschel, J. Poater, H. Dengel, F. M. Bickelhaupt and C. Lichtenberg, Angew. Chem., Int. Ed., 2018, 57, 38253829; (b) B. Ritschel and C. Lichtenberg, Synlett, 2018, 29, 2213-2217.

20 (a) R. J. Schwamm, B. M. Day, M. P. Coles and C. M. Fitchett, Inorg. Chem., 2014, 53, 3778-3787; (b) R. J. Schwamm, M. P. Coles and C. M. Fitchett, Dalton Trans., 2017, 46, 4066-4074; (c) C. Hering-Junghans, M. Thomas, A. Villinger and A. Schulz, Chem.-Eur. J., 2015, 21, 67136717; (d) M. Veith, B. Bertsch and V. Huch, Z. Anorg. Allg. Chem., 1988, 559, 73-88.

21 For examples of intermediate carbamoyl radical species in synthetic chemistry see: (a) F. Minisci, F. Fontana, F. Coppa and Y. M. Yan, J. Org. Chem., 1995, 60, 54305433; (b) Q.-F. Bai, C. Jin, J.-Y. He and G. Feng, Org. Lett., 2018, 20, 2172-2175; (c) G. López-Valdez, S. Olguín-Uribe and L. D. Miranda, Tetrahedron Lett., 2007, 48, 8285-8289.

22 Compounds 1 and 2 represent contact ion pairs in the solid state; the term "cationic species" is used to describe the weak interactions between the triflate anions and the bismuth atoms in these compounds.

23 The solid that precipitated from THF was analyzed by NMR spectroscopy in $\mathrm{NC}_{5} \mathrm{D}_{5}$. The spectrum showed all resonances for compound 2 (except for those due to $\mathrm{NC}_{5} \mathrm{H}_{5}$ ) plus resonances for non-coordinate THF. This supports our results from DFT calculations suggesting that the precipitate is compound $\mathbf{I}-\mathbf{5}$.

$24 \mathrm{~A}^{13} \mathrm{C}$ NMR chemical shift of $204.5 \mathrm{ppm}$ has been reported for $\mathrm{CO}$ groups in the five-membered cyclic complex anion $\left[\mathrm{As}[\mathrm{C}(\mathrm{O})]_{2}[\mathrm{NDipp}]_{2}\right]^{-}$: A. Hinz and J. M. Goicoechea, Angew. Chem., Int. Ed., 2016, 55, 8536-8541.
25 (a) L. C. Willemsens, J. Organomet. Chem., 1971, 27, 45-51; (b) G.-E. Matsubayashi, M. Hiroshima and T. Tanaka, J. Organomet. Chem., 1973, 59, 207-212.

26 The formation of a bismuth carbamoyl species from $\mathrm{BiCl}_{3}$, DMF and amines has been discussed on the basis of conductance measurements and elemental analysis, but no spectroscopic or structural data has been provided: A. K. Mishra and K. N. Tandon, Inorg. Chem., 1971, 10, 1896-1899.

27 (a) B. Murray, J. Hvoslef, H. Hope and P. P. Power, Inorg. Chem., 1983, 22, 3421-3424; (b) C. Lichtenberg, F. Pan, T. P. Spaniol, U. Englert and J. Okuda, Angew. Chem., Int. Ed., 2012, 51, 13011-13015; (c) S. Solyntjes, J. Bader, B. Neumann, H.-G. Stammler, N. Ignat'ev and B. Hoge, Chem.-Eur. J., 2017, 23, 1557-1567.

28 A. W. Addison, T. N. Rao, J. Reedijk, J. van Rijn and G. C. Verschoor, J. Chem. Soc., Dalton Trans., 1984, 13491356.

29 (a) R. J. Schwamm, J. R. Harmer, M. Lein, C. M. Fitchett, S. Granville and M. P. Coles, Angew. Chem., Int. Ed., 2015, 54, 10630-10633; (b) C. Ganesamoorthy, C. Helling, C. Wölper, W. Frank, E. Bill, G. E. Cutsail III and S. Schulz, Nat. Commun., 2018, 9, 87.

30 For electrochemical studies on dibismuthenes including a ferrocenyl substituted derivative see: (a) M. Sakagami, T. Sasamori, H. Sakai, Y. Furukawa and N. Tokitoh, Chem.Asian J., 2013, 8, 690-693; (b) T. Sasamori, E. Mieda, N. Nagahora, K. Sato, D. Shiomi, T. Takui, Y. Hosoi, Y. Furukawa, N. Takagi, S. Nagase and N. Tokitoh, J. Am. Chem. Soc., 2006, 128, 12582-12588.

31 Relativistic, dispersion-corrected DFT calculations were carried out at the ZORA-BLYP-D3BJ/TZ2P level of theory using COSMO to simulate solvation in THF, as implemented in the ADF program, see: $(a)$ G. te Velde, F. M. Bickelhaupt, E. J. Baerends, C. Fonseca Guerra, S. J. A. van Gisbergen, J. G. Snijders and T. Ziegler, J. Comput. Chem., 2001, 22, 931-967; (b) F. M. Bickelhaupt and E. J. Baerends, in Reviews in Computational Chemistry, ed. K. B. Lipkowitz and D. B. Boyd, Wiley-VCH, New York, 2000, vol. 15, pp. 1-86.

32 Substitution of the two terminal thf ligands in $\mathbf{1}$ for two CO molecules was calculated to be endothermal and endergonic $\left(\Delta H:+18.0 \mathrm{kcal} \mathrm{mol}^{-1} ; \Delta G:+16.2 \mathrm{kcal} \mathrm{mol}^{-1}\right)$ and is therefore suggested not to be involved in the primary reaction pathway (formation of "I-1_2CO", ESI $\dagger$ ).

33 (a) M. Ryang and S. Tsutsumi, Bull. Chem. Soc. Jpn., 1962, 35, 1121-1124; (b) H. C. Brown and E. Negishi, J. Am. Chem. Soc., 1967, 89, 5477-5478; (c) N. S. Nudelman and A. A. Vitale, J. Org. Chem., 1981, 46, 4625-4626; (d) D. Seyferth and R. M. Weinstein, J. Am. Chem. Soc., 1982, 104, 5534-5535; (e) W. J. J. M. Sprangers and R. Louw, J. Chem. Soc., Perkin Trans. 2, 1976, 1895-1901; (f) M. D. Anker, C. E. Kefalidis, Y. Yang, J. Fang, M. S. Hill, M. F. Mahon and L. Maron, J. Am. Chem. Soc., 2017, 139, 10036-10054; (g) M. A. Dureen and D. W. Stephan, J. Am. Chem. Soc., 2010, 132, 1355913568; (h) M. R. Mason, B. Song and K. Kirschbaum, J. Am. Chem. Soc., 2004, 126, 11812-11813; (i) X. Li, C. Ni, 
H. Song and C. Cui, Chem. Commun., 2006, 1763-1765; (j) M. R. Mason, B. Song, Y. Han and X. Hu, Inorg. Chim. Acta, 2008, 361, 3332-3337; (k) C. M. Lindsay and D. A. Widdowson, J. Chem. Soc., Perkin Trans. 1, 1988, 569573.

34 An FLP type reactivity towards CO has recently been reported for a phosphorus ylide with a boryl substituent: M. Radius and F. Breher, Chem.-Eur. J., 2018, 24, 15744-15749.

35 (a) X. Wang, Z. Zhu, Y. Peng, H. Lei, J. C. Fettinger and P. P. Power, J. Am. Chem. Soc., 2009, 131, 6912-6913; (b) Z. D. Brown and P. P. Power, Inorg. Chem., 2013, 52, 62486259.

36 (a) H. Braunschweig, T. Dellermann, R. D. Dewhurst, W. C. Ewing, K. Hammond, J. O. C. Jimenez-Halla, T. Kramer, I. Krummenacher, J. Mies, A.-K. Phukan and A. Vargas, Nat. Chem., 2013, 5, 1025-1028; (b) M. Arrowsmith, J. Böhnke, H. Braunschweig and M. A. Celik, Angew. Chem., Int. Ed., 2017, 56, 14287-14292; (c) N. Nakata, T. Oikawa, T. Matsumoto, Y. Kabe and A. Sekiguchi, Organometallics, 2005, 24, 3368-3370; (d) H. Zhang, Z. Cao, W. Wu and Y. Mo, Angew. Chem., Int. Ed., 2018, 57, 13076-13081; (e) L. Wallbaum, D. Weismann, D. Löber, C. Bruhn, P. Prochnow, J. E. Bandow and U. Siemeling, Chem.-Eur. J., 2019, 25, 1488-1497.

37 Carbenes and silylenes also form stable and transient (sila-) ketenes with CO, respectively: (a) V. Lavallo, Y. Canac, B. Donnadieu, W. W. Schoeller and G. Bertrand, Angew. Chem., Int. Ed., 2006, 45, 3488-3491; (b) M. Tacke, C. Klein, D. J. Stufkens, A. Oskam, P. Jutzi and E. A. Bunte, Z. Anorg. Allg. Chem., 1993, 619, 865-868; (c) M.-A. Pearsall and R. West, J. Am. Chem. Soc., 1988, 110, 7228-7229; (d) R. Becerra and R. Walsh, J. Am. Chem. Soc., 2000, 122, 3246-3247.

38 (a) M. Sajid, A. Lawzer, W. Dong, C. Rosorius, W. Sander, B. Schirmer, S. Grimme, C. G. Daniliuc, G. Kehr and G. Erker, J. Am. Chem. Soc., 2013, 135, 18567-18574; (b) M. Sajid, L.-M. Elmer, C. Rosorius, C. G. Daniliuc, S. Grimme, G. Kehr and G. Erker, Angew. Chem., Int. Ed., 2013, 52, 2243-2246; (c) L.-M. Elmer, G. Kehr, C. G. Daniliuc, M. Siedow, H. Eckert, M. Tesch, A. Studer, K. Williams, T. H. Warren and G. Erker, Chem.-Eur. J., 2017, 23, 6056-6068; (d) L. Wang, K. Samigullin, M. Wagner, A. C. McQuilken, T. H. Warren, C. Daniliuc, G. Kehr and G. Erker, Chem.-Eur. J., 2016, 22, 1101511021; (e) K.-Y. Ye, G. Kehr, C. G. Daniliuc, L. Liu, S. Grimme and G. Erker, Angew. Chem., Int. Ed., 2016, 55, 9216-9219.

39 Also see reaction of $\left(\mathrm{P}(t \mathrm{Bu})_{3}+2 \mathrm{~B}\left(\mathrm{C}_{6} \mathrm{~F}_{5}\right)_{3}\right)$ with syngas: R. Dobrovetsky and D. W. Stephan, J. Am. Chem. Soc., 2013, 135, 4974-4977.
40 For examples of phosphorus compounds reacting with carbonyl ligands see: (a) A. Fuchs, D. Gudat, M. Nieger, O. Schmidt, M. Sebastian, L. Nyulaszi and E. Niecke, Chem.-Eur. J., 2002, 8, 2188-2196; (b) L. Weber, K. Reizig and R. Boese, Angew. Chem., Int. Ed., 1986, 25, 755-757; (c) A. Marinetti, J. Fischer and F. Mathey, J. Am. Chem. Soc., 1985, 107, 5001-5002; (d) M. Scheer, E. Leiner, P. Kramkowski, M. Schiffer and G. A. Baum, Chem.-Eur. J., 1998, 4, 1917-1934; (e) M. Finze, E. Bernhardt, H. Willner and C. W. Lehmann, Inorg. Chem., 2006, 45, 669-678.

41 For examples of metal complexes with phosphorus ligands reacting with CO, see: (a) P. G. Edwards, M. B. Hursthouse, K. M. A. Malik and J. S. Parry, J. Chem. Soc., Chem. Commun., 1994, 1249-1250; (b) D. M. Roddick, B. D. Santariero and J. E. Bercaw, J. Am. Chem. Soc., 1985, 107, 4670-4678; (c) R. L. De, D. Wolters and H. Vahrenkamp, Z. Naturforsch., 1986, 41b, 283-291.

42 For an example of Pd-catalyzed synthesis of acylphosphonates using CO as a C1-source see: Y. Masuda, N. Ishida and M. Murakami, Chem.-Asian J., 2015, 10, 321324.

43 For an example of reversible coordination of $\mathrm{CO}$ to a phosphinidene see: M. Hansmann and G. Bertrand, J. Am. Chem. Soc., 2016, 138, 15885-15888.

44 A. Hinz, A. Schulz and A. Villinger, Angew. Chem., Int. Ed., 2015, 54, 2776-2779.

45 (a) D. W. Stephan, J. Am. Chem. Soc., 2015, 137, 10018-10032; (b) D. W. Stephan, Acc. Chem. Res., 2015, 48, 306-316; (c) D. W. Stephan and G. Erker, Chem. Sci., 2014, 5, 26252641; (d) F.-G. Fontaine and D. W. Stephan, Philos. Trans. R. Soc., A, 2017, 375, 20170004.

46 A 1-phosphane-8-stibonium-naphtalene species with Lewis acidic character has been reported, but no FLP-type reactivity has been described to date: (a) R. A. Ugarte, D. Devarajan, R. M. Mushinski and T. W. Hudnall, Dalton Trans., 2016, 45, 11150-11161; (b) R. A. Ugarte and T. W. Hudnall, Green Chem., 2017, 19, 1990-1998.

47 In the heterogeneously catalyzed photocatalytic reduction of $\mathrm{CO}_{2}$, the reactivity of frustrated Lewis pairs of $\operatorname{In}_{2} \mathrm{O}_{3-x}(\mathrm{OH})_{y}$ has been modified by isomorphous substitution of In by Bi: Y. Dong, K. K. Ghuman, R. Popescu, P. N. Duchesne, W. Zhou, J. Y. Y. Loh, A. A. Jelle, J. Jia, D. Wang, X. Mu, C. Kübel, L. Wang, L. He, M. Ghoussoub, Q. Wang, T. E. Wood, L. M. Reyes, P. Zhang, N. P. Kherani, C. V. Singh and G. A. Ozin, Adv. Sci., 2018, 5, 17007431700742.

48 M. Seidl, M. Schiffer, M. Bodensteiner, A. Y. Timoshkin and M. Scheer, Chem.-Eur. J., 2013, 19, 13783-13791.

49 W. Lu, H. Hu, Y. Li, R. Ganguly and R. Kinjo, J. Am. Chem. Soc., 2016, 138, 6650-6661. 